\title{
Gadolinium and Multiple Sclerosis: Vessels, Barriers of the Brain, and Glymphatics
}

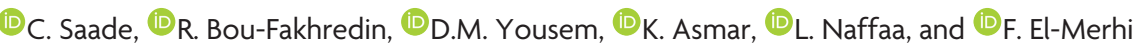

ON

\begin{abstract}
SUMMARY: The pathogenesis of multiple sclerosis is characterized by a cascade of pathobiologic events, ranging from focal lymphocytic infiltration and microglia activation to demyelination and axonal degeneration. MS has several of the hallmarks of an inflammatory autoimmune disorder, including breakdown of the BBB. Gadolinium-enhanced MR imaging is currently the reference standard to detect active inflammatory lesions in MS. Knowledge of the patterns and mechanisms of contrast enhancement is vital to limit the radiologic differential diagnosis in the staging and evaluation of MS lesion activity. The aim of this review was the following: 1) to outline the pathophysiology of the effect of lymphocyte-driven inflammation in MS, 2) to describe the effects of gadolinium on the BBB and glymphatic system, and 3) to describe gadolinium enhancement patterns and artifacts that can mimic lesions in MS.
\end{abstract}

ABBREVIATIONS: $\mathrm{Gd}^{3+}=$ gadolinium; MTR $=$ magnetization transfer ratio

M R imaging is used as paraclinical supporting evidence of MS and has become an established tool for disease monitoring. ${ }^{1}$ It is used to guide treatment by identifying poor responders during follow-up of lesions in the white matter tracts and gray matter, ${ }^{2}$ which is important given that MS is a chronic disease. Technically, challenges remain in standardizing MR imaging scanner and contrast media protocols to better characterize and follow lesions during disease progression.

Gadolinium enhancement is used to depict the early inflammatory phase of MS lesions, which is primarily dependent on 2 key conditions: First, there must be sufficient inflammation surrounding the MS lesion, and, second, the time lapse between gadolinium $\left(\mathrm{Gd}^{3+}\right)$ injection and image acquisition allows the $\mathrm{Gd}^{3+}$ molecule to traverse the disrupted BBB and glymphatic system into the lesions (See On-line Appendix for more on Gadolinium enhancement). ${ }^{3}$ The aim of this review was the following: 1) to outline the pathophysiology of lymphocyte-driven inflammation

Received August 25, 2017; accepted after revision June 5, 2018.

From the Diagnostic Radiology Department (C.S., R.B.-F., K.A., L.N., F.E.-M.), American University of Beirut Medical Center, Beirut, Lebanon; and The Russell H. Morgan Department of Radiology and Radiological Science (D.M.Y.), Neuroradiology Division, Johns Hopkins Hospital, Baltimore, Maryland.

Please address correspondence to Fadi El-Merhi, MD, ABR, Diagnostic Radiology Department, American University of Beirut Medical Center, Beirut, Lebanon, PO Box 11-0236 Riad El-Solh, Beirut, 1107 2020, Lebanon; e-mail: fe19@aub.edu.lb

- Indicates open access to non-subscribers at www.ajnr.org

Indicates article with supplemental on-line appendix and table.

Indicates article with supplemental on-line photo.

http://dx.doi.org/10.3174/ajnr.A5773 in MS, 2) to describe the effects of $\mathrm{Gd}^{3+}$ on the BBB and glymphatic system, and 3) to describe $\mathrm{Gd}^{3+}$ enhancement patterns and artifacts that can obscure the detection of MS plaques.

\section{Lymphocyte-Driven Inflammation and Microglial Activation}

Lymphocyte-driven inflammation and microglial activation play central roles in the pathophysiology of MS. The inflammatory plaques characteristic of MS comprise a wide variation of immunologic and pathologic features. ${ }^{4}$

At the early stages of MS, acute plaques are a common finding. They typically consist of robust inflammatory infiltration with demyelination throughout the lesion. ${ }^{5}$ The inflammatory components at this stage are mainly T-lymphocytes, monocytes, and macrophages, and their influx is centered around vessels (perivascular cuffing). Foamy macrophages can also be found distributed throughout the lesion because they contribute to active stripping of myelin from axons. ${ }^{4}$ Even though the axon itself is usually spared, it is common to find extensive axonal injury in these lesions, and despite prominent glial reactivity, dense glial scarring is not typical.

When MS plaques become chronic, the lesions are predominantly hypocellular with obvious glial scarring and loss of myelin.

The inflammatory progression of MS can be clarified by a recent typing of MS lesions based on the pattern of leukocyte markers, myelin proteins, immunoglobulin, and complement proteins present in the lesions. Pattern 1 has predominant T-cell and macrophage inflammatory content. Pattern 2 has T-cell and macrophage infiltration with immunoglobulin and myelin degradation products in the macrophages. Pattern 3 has obvious oligodendro- 

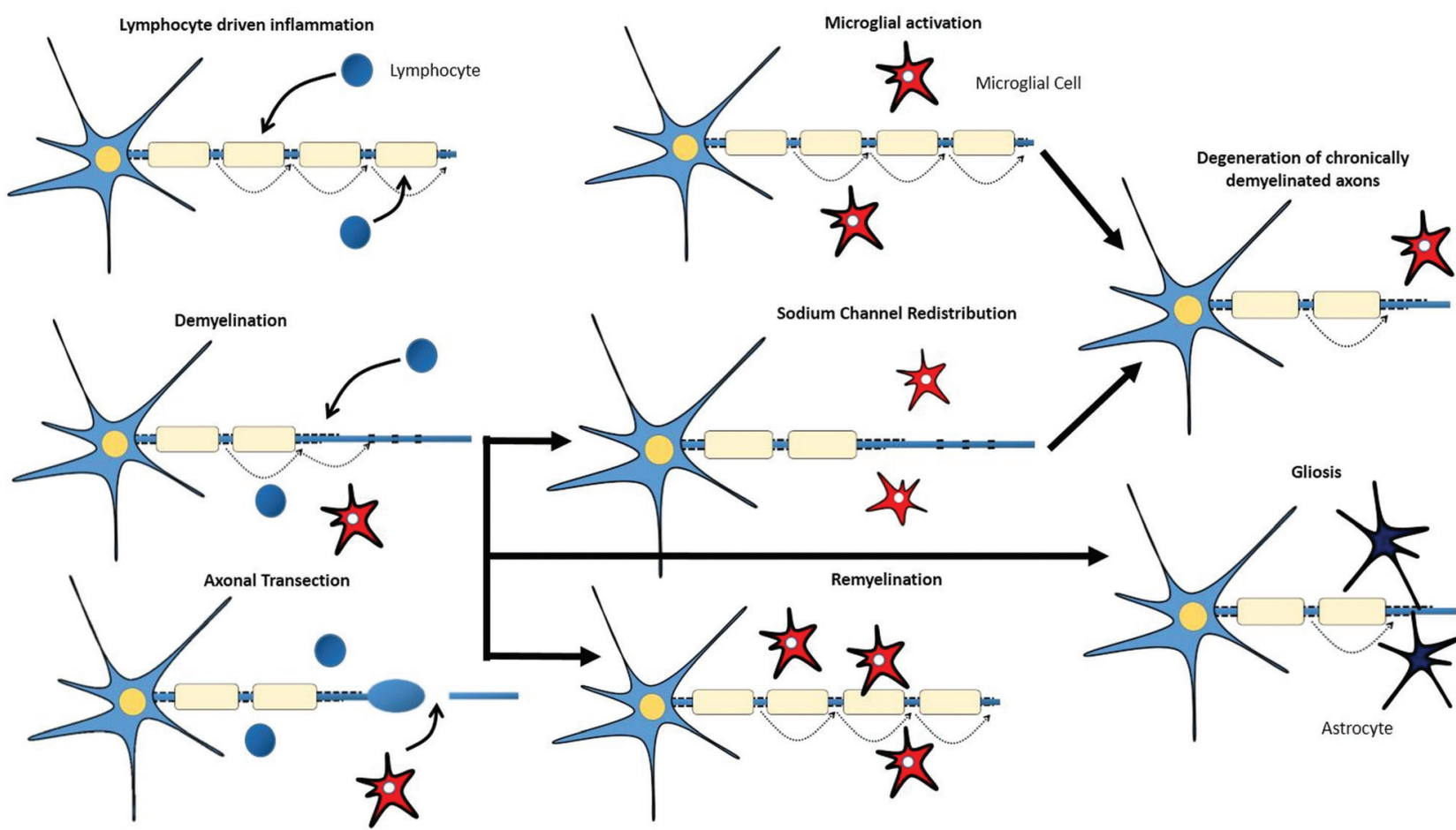
demyelinated axons
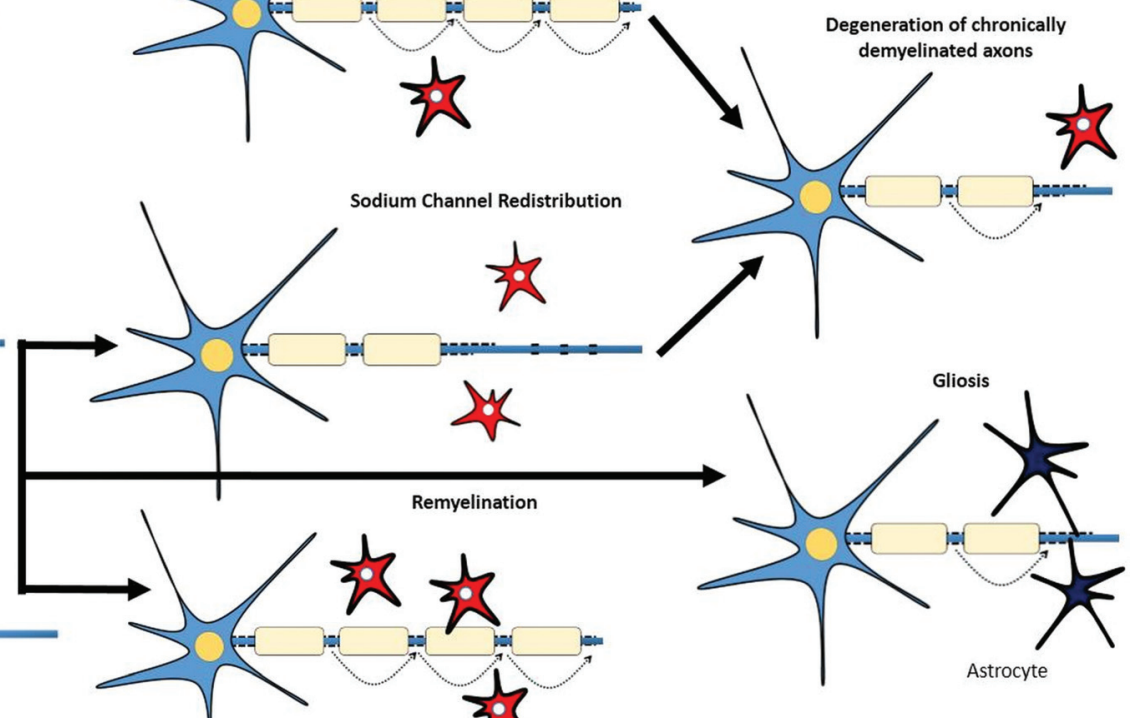

FIG 1. Lymphocyte-driven inflammation induces conduction blocks in structurally intact axons, drives demyelination, and induces transection of axons (with consequent conduction block) within acute lesions. Activated microglial cells might contribute to the repair mechanisms that lead to remyelination or to the degeneration of axons. Redistribution of sodium channels along demyelinated axons could restore conduction. Astrocytic activation and proliferation (gliosis) might impede repair.

cyte loss at the active edge of the lesion with loss of myelin-associated glycoprotein. Pattern 4 has oligodendrocyte dystrophy and absence of remyelination. ${ }^{6}$

The pathogenesis of MS is still a poorly understood mechanism. One hypothesis states that the initial event during plaque genesis is an early intrinsic oligodendrocyte injury that leads to the inflammatory damage associated with MS. This hypothesis seems to be supported, to a certain extent, by a study ${ }^{7}$ that found that the tissue immediately adjacent to lesion borders showed microscopic evidence of cellular injury without the presence of immune infiltration. It is well-established is that MS is an immune-mediated destruction of CNS components.

\section{Role of T-Lymphocytes in MS}

The presence of lymphocytes in MS suggests an antigen-specific targeting of myelin in this disease. T-cells isolated from patients with MS have been shown to react to a variety of antigens of myelin origin like myelin basic protein, proteolipid protein, myelin oligodendrocyte glycoprotein, and myelin oligodendrocytic basic protein. ${ }^{8-12}$ In addition, many nonmyelin antigens and neuronal antigens have also been described. The exact mechanism causing the T-cells to become abnormally activated is still elusive, but molecular mimicry has been suspected. Another culprit is interleukin 17. Interleukin 17-secreting cells were found in the CSF of a patient with MS, ${ }^{13}$ and the percentage of interleukin 17 producing memory CD4 T-cells was elevated in the peripheral blood of patients with MS. ${ }^{14}$ Interleukin 17 gene expression is also elevated in lesions of patients with MS, thus suggesting a high association between this interleukin and MS pathogenesis, especially with the lymphocyte T helper 17 being a critical mediator of the immune destruction of myelin and axons in MS. ${ }^{15}$ In addition, T helper 17 cells have been shown to cross the BBB more efficiently than other T-cells, and the presence of interleukin 17secreting CD4 T-cells has been shown to be capable of causing damage to the $\mathrm{BBB},{ }^{16}$ which contributes to the influx of inflammatory cells into the brain.

In response to inflammation, injury, and axonal degeneration, microglial cells, which represent the macrophages resident in the CNS parenchyma, become activated. ${ }^{17}$ When activated, these microglial cells can adopt diverse phenotypes, which can be benign, protective, or contributory to neurodegeneration (Fig 1). ${ }^{18,19}$ The pathogenesis of MS is characterized by not only lymphocytedriven inflammation and microglial activation but also demyelination, remyelination, axonal degeneration, and gliotic response.

Demyelination and Remyelination. Demyelination is a hallmark of MS and occurs in GM and WM lesions (Fig 1). The inflammatory process, characterized by a breakdown in the BBB, inflammatory cell infiltrates, and production of immune-soluble mediators and harmful inflammatory enzymes, can lead to the development of acute demyelinating lesions. Acute demyelination is the main determinant for the conduction block that creates the acute neurologic deficit. Additionally, demyelinated axons can become hyperexcitable and spontaneously generate impulses that translate into the positive symptoms of MS. ${ }^{18}$

The most valuable role of remyelination could be to ensure axonal survival for the long term rather than the immediate restoration of nerve conduction (Fig 1). Low levels of remyelination are seen in most patients with MS. ${ }^{20}$ Oligodendrocyte precursors are available even in chronic lesions of patients with progressive 
MS, suggesting that their availability is not the limiting factor for remyelination. ${ }^{21}$ Therefore, several reasons for remyelination failure might exist, including recurrent demyelination in previously remyelinated areas. ${ }^{18}$

Axonal Degeneration and Neuronal Damage. Axonal loss can occur acutely in new inflammatory lesions but also across time in chronic, demyelinated lesions (Fig 1). ${ }^{1}$ Mechanisms that link inflammation to axonal loss include neuronal energy deficit or the loss of myelin trophic support. ${ }^{20,22} \mathrm{CD} 8$-positive T-cells are suspects in the immune-mediated axonal damage witnessed in MS, possibly via the release of cytotoxic granules, induction of apoptosis (activating surface receptors like Fas), or release of cytokines like tumor necrosis factor- $\alpha$. The innate immune system also seems to play a role via the toll-like receptors. ${ }^{23,24}$ Autoantibodies have also been linked to axonal injury in MS. ${ }^{25}$ The axon in this situation is at high risk of irreversible damage because higher energy demands on demyelinated axons and glutamate-mediated excitotoxicity are a consequence of immune injury to myelin. ${ }^{26}$

Gliotic Response. The gliotic response is the process of hypertrophy and proliferation of astrocytes seen within and at the margins of inflammatory demyelinating lesions and also in normal-appearing WM (Fig 1). It is generally thought to be secondary to neuronal damage and apoptosis of oligodendrocytes ${ }^{27}$ and to contribute to irreversible (chronic) symptoms. ${ }^{18}$

T2-weighted sequences, whether true T2-weighted or FLAIR sequences, are useful for identifying the number and size of WM lesions, but often they cannot determine the activity level of a plaque in and of itself. ${ }^{28}$ T1-weighted imaging without contrast helps detect late MS lesions that appear hypointense on MR imaging and demonstrate irreversible axonal pathology. ${ }^{28} \mathrm{~T} 1-$ weighted sequences with $\mathrm{Gd}^{3+}$ detect BBB breakdown, which occurs with active inflammation.

The current diagnostic criteria of MS are based on the detection of CNS lesions demonstrating dissemination in space and time. Several criteria aim to quantify the parameters involved in the dissemination in space and time. The $2005 \mathrm{McD}$ onald criteria reported a sensitivity and specificity of $77 \%$ and $90 \%$, respectively. ${ }^{29}$ The newly revised $2010 \mathrm{McD}$ onald criteria demonstrated sensitivity and specificity of $100 \%$ and $86 \%$, respectively, for children older than 11 years of age with symptoms inconsistent with acute disseminated encephalomyelitis. ${ }^{30}$ The Swanton criteria for dissemination in space reported a sensitivity and specificity of $71 \%$ and $86 \%$, respectively. ${ }^{31}$ In Europe, radiologists have adopted the Magnetic Resonance Imaging in MS modification with the following changes: 1) Optic neuritis is added to 4 locations in McDonald criteria, 2) $\geq 3$ periventricular lesions are required, 3 ) cortical and juxtacortical lesions are considered qualifying, and 4) dissemination in time does not need to be asymptomatic or symptomatic, and any new lesion or enhancing/nonenhancing lesions in the same study qualify.

\section{Gadolinium Effects}

BBB. Gadolinium distribution into the neural tissue is complex because it occurs by a variety of mechanisms. To ensure adequate oxygen delivery to the highly metabolically active neurons, the capillary network of the brain is dense. A unique distinguishing feature of the brain microvasculature is the presence of tight junctions between the adjacent endothelial cells lining the capillaries. The BBB exists at all levels of the vascular tree within the CNS, including the penetrating arteries and arterioles, the dense capillary bed, the postcapillary venules, and the draining venules and veins. $^{32,33}$ Although each vascular segment needs to maintain tight barrier properties to insulate the neural tissue from the blood, there are specializations within the vascular bed that are crucial for BBB function.

The BBB is a multicellular vascular structure that separates the CNS from the peripheral blood circulation. It is regulated by the interchange among the main compartments of the CNS, brain, CSF, and blood by a combination of physical and functional mechanisms. There are 4 main interfaces in the BBB: 1) the BBB proper at the level of the cerebral endothelial cells that allows highly lipophilic solutes such as caffeine to pass the BBB, 2) the blood-CSF barrier at the epithelial cells of the choroid plexuses within the 4 cerebral ventricles, 3 ) the pia arachnoid, and 4) an additional barrier interface present only in the early brain development between the CSF and the brain interstitial fluid (Fig 2). BBB dysfunction can lead to ion dysregulation, altered signaling homeostasis, and entry of immune cells and molecules into the CNS, processes that lead to neuronal dysfunction and degeneration. ${ }^{33}$

Blood supply to both WM and GM occurs with the primary vessels crossing the pia mater into the GM. However, in patients with MS, capillary density is relatively maintained, but with decreased cerebral blood flow resulting from numerous string vessels. ${ }^{34}$ String vessels are thin connective tissue strands, remnants of capillaries, with no endothelial cells, because they do not carry blood. Whether string vessels are the cause or effect of GM hypoperfusion and eventual brain atrophy is unknown. Another potential hypothesis is that inflammatory processes can result in microvascular damage by different mechanisms: Cytotoxic Tcells may recognize antigens on endothelial cells and activate a clotting cascade, which, in turn, leads to thrombosis. ${ }^{35}$ Additionally, evidence ${ }^{36}$ suggests that parenchymal plaques may initially be associated with capillaries and arterioles in an attempt to seal microvascular leakage, especially during inflammation. Finally, in advanced stages of inflammation, the pressure exerted by the growing perivascular amyloid deposits constricts the microvessel, leaving dysfunctional capillary stumps and string vessels.

Glymphatic System. An indirect mechanism of $\mathrm{Gd}^{3+}$ distribution occurs via the glymphatic system, which is a highly polarized macroscopic system of convective fluid fluxes with rapid interchange of CSF and interstitial fluid. This exchange is facilitated by a convective influx of CSF along the periarterial space. CSF, from the subarachnoid space, is driven into the Virchow-Robin perivascular spaces by a combination of arterial pulsatility, slow vasomotion, respiration, and CSF pressure gradients. The loose fibrous matrix of the perivascular space can be viewed as a lowresistance highway for CSF influx. The subsequent transport of CSF into the dense and complex brain parenchyma is facilitated by astrocytic aquaporin- 4 water channels expressed in a highly polarized manner in astrocytic end-feet that ensheathe the brain vasculature. ${ }^{37-39}$ CSF movement into the parenchyma drives convective interstitial fluid fluxes within the tissue toward the 

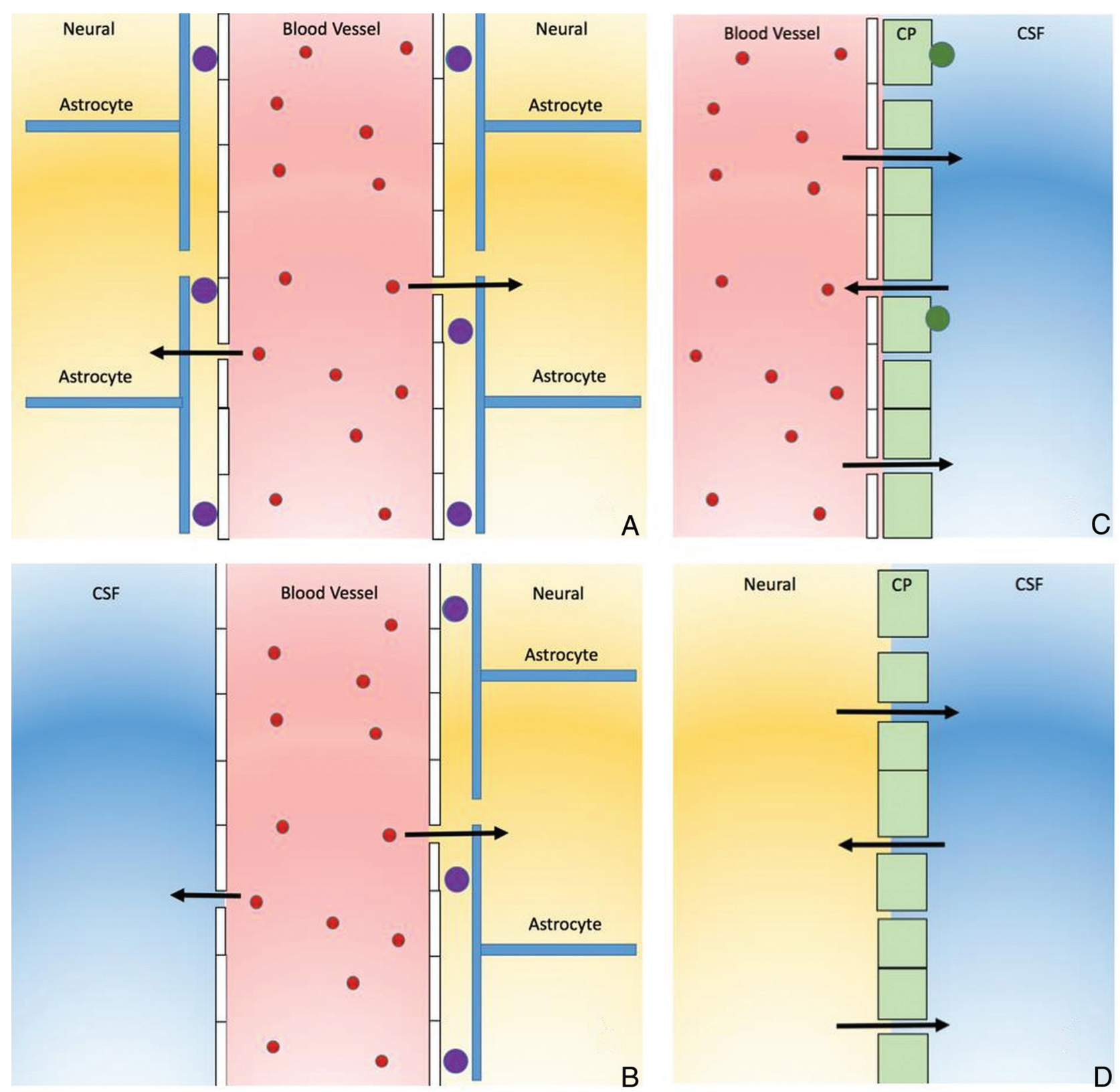

FIG 2. The 4 main interfaces of the blood-brain barrier. $A$, The blood-brain barrier proper is formed by tight junctions between the endothelial cells of the cerebral vasculature. It is thought that pericytes (purple circles) are sufficient to induce some barrier characteristics in endothelial cells, while astrocytes are able to maintain the integrity of the blood-brain barrier postnatally. $B$, The outer CSF-brain barrier and the level of the pia arachnoid are formed by tight junctions between endothelial cells of the arachnoid vessels. C, The blood-CSF barrier is formed by tight junctions between epithelial cells of the choroid plexus (CP) (note that the plexus vasculature is fenestrated). Resident epiplexus (green circles) immune cells are present on the CSF-surface of the plexus epithelium. $D$, The inner CSF-brain barrier, present only in early development, is formed by strap junctions between the neuroependymal cells lining the ventricular surfaces. In the adult, this barrier is no longer present.

perivenous spaces surrounding the large deep veins. The interstitial fluid is then collected in the perivenous space from where it drains out of the brain and toward the cervical venous system. The glymphatic system provides a paravascular, transparenchymal outflow passage, which helps remove brain metabolites ${ }^{40}$ such as amyloid $\beta$ and inulin ${ }^{41}$ found in the CSF. The paravascular space comprises the compartment between the pia mater and glia limitans, which encompasses the vascular wall of the leptomeningeal vein. The paravascular space however, is in direct contact with the extracellular space and the subarachnoid space of the leptomeningeal artery. The inflow of CSF in the paravascular space is along the arteries and exits through the veins, where it is mixed with interstitial fluid. ${ }^{42}$

The clearance of excess metabolites is essential for tissue homeostasis $^{41}$ and is meditated by the CSF-interstitial fluid exchange pathway. Furthermore, studies on rodent brains have demonstrated that the primary, most rapid glymphatic inflow occurs at the level of the hypothalamus, olfactory tract, retrosplenial cortex, pons, amygdala, cerebellum, and hippocampus. ${ }^{43}$ The glymphatic system is also dependent on the intensity by which the pulse is generated throughout the smooth-muscle cells of the arteries. Particular to arteries, pulsation that is often generated by 


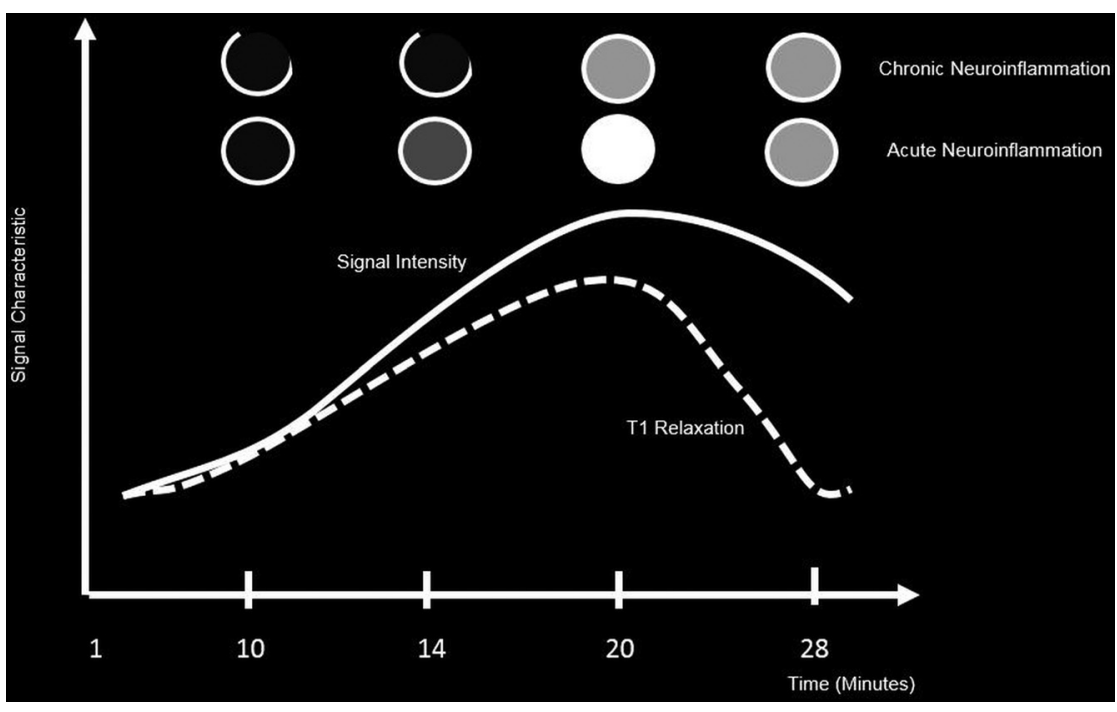

FIG 3. Enhancement patterns of lesions across time depicting signal intensity versus T7 relaxation times of acute and chronic MS lesions.

smooth-muscle cells creates pulse waves along the whole length of the pial artery and penetrating arteries diving into the brain from the cortical surface. ${ }^{38,44}$ It has been shown that adrenergic agonists such as dobutamine increase the pulsatile effect significantly when administered to mice and result in a larger amount of CSF penetration into the parenchyma. ${ }^{32,41}$ The opposite effect was obtained when arterial pulsatility was dampened by internal carotid artery ligation. Additionally, the reduction of pulse waves decreased CSF-interstitial fluid exchange. ${ }^{38}$ This feature suggests that glymphatic activity, at least in part, is driven by arterial pulsatility and explains why perivascular influx occurs preferentially around pulsating arteries and not cerebral veins.

The parameters that aid in the facilitation of flow in the glymphatic system mainly include cell volume, pulsatility, astrocytic aquaporin- 4 channels, water channel positions, ${ }^{43}$ and sleep state. ${ }^{41}$ Studies have shown that for one to fully understand the glymphatic system, small-molecular-weight tracers need to be administered to penetrate the cortical and basal arteries to reach the capillaries and, finally, interstitial compartments. This method will provide a clear pathway for the paravascular space in the glymphatic system that could be detected by different imaging techniques. ${ }^{43}$ Studies have shown that tracers injected into the paravascular space are only evident along the arteries and not veins and are characterized as being bidirectional, depending of the site of injection. Moreover, large tracers do not penetrate the paravascular space, and their flow is affected by the aquaporin- 4 and pulsation mechanism. ${ }^{42}$

The glymphatic system has been implicated in the discovery of deposition of $\mathrm{Gd}^{3+}$ in the dentate nucleus. ${ }^{45}$ Eide and Ringstad ${ }^{40}$ evaluated patients who had $\mathrm{Gd}^{3+}$ administrations in the subarachnoid space with MR imaging. Four hours after $\mathrm{Gd}^{3+}$ administration in the subarachnoid space, both the cortical GM and WM of the brain demonstrated increased signal intensity and the $\mathrm{Gd}^{3+}$ was surmised to enter the human brain through the glymphatic system. Naganawa et $\mathrm{al}^{46}$ evaluated the brain MR imaging of 27 subjects who had been administered $\mathrm{Gd}^{3+} 4$ hours prior. On the postcontrast FLAIR image, the subarachnoid and perivascular spaces showed increased signal intensity, subsequent to $\mathrm{Gd}^{3+}$ transfer to the subarachnoid and perivascular spaces. These results demonstrate that intravenously administered $\mathrm{Gd}^{3+}$ can be transported through the glymphatic system to reach the brain. However, the association between the hyperintensity of the dentate nucleus and the $\mathrm{Gd}^{3+}$ transported through the glymphatic system is still unclear. The glymphatic system transports all low-molecular-weight materials passively, and both the linear and macrocyclic $\mathrm{Gd}^{3+}$ is transported in the same way. ${ }^{45}$ However, the signal intensity of the dentate nucleus varies according to the type of administered $\mathrm{Gd}^{3+} \cdot{ }^{45,47}$ In addition, the distribution of $\mathrm{Gd}^{3+}$ cannot be explained by passive transportation. The accumulation of $\mathrm{Gd}^{3+}$ in the brain is probably due, to some extent, to the glymphatic system, but the association between the glymphatic system and hyperintensity of the dentate nucleus remains unclear and controversial. ${ }^{47}$

The impact of double and triple doses of $\mathrm{Gd}^{3+}$ has been investigated to determine lesion activity and active plaque numbers. Gasperini et $\mathrm{al}^{48}$ compared the number and volume of MS lesions when the patient was administered double and triple doses of gadolinium. The volume of lesion enhancement with a triple dose was higher compared with the double dose (1.9 versus $1.7 \mathrm{~mL}$ ). However, they concluded that the double dose provided similar sensitivity with lower cost and improved safety than triple dose studies for MS detection. Additionally, in a recent study, ${ }^{49}$ it was concluded that macrocyclic $\mathrm{Gd}^{3+}$ deposition is reduced but not completely eliminated when macrocyclic $\mathrm{Gd}^{3+}$ is used compared with linear agents. Thus, in light of the previous studies, double and triple doses of $\mathrm{Gd}^{3+}$ pose greater risk than benefit to the patient in MS imaging.

\section{Enhancement Patterns and Lesion Characteristics}

The cause of the enhancement in MS is inflammation, which most often is limited to perivenular inflammation; there is no neovascularity and no angiogenesis. Therefore, enhancement of MS plaques may be faint, the lesions usually do not produce any perilesional vasogenic edema, and the enhancing rim is either thin and often incomplete or solidly enhancing. ${ }^{50}$ Additionally, enhancement may not occur when there is a low level of inflammation. The degree of enhancement of MS lesions is an indicator of the degree of active inflammation and distinguishes between old and new lesions by identifying areas of active BBB breakdown (Fig 3). ${ }^{51}$

MR imaging has revealed that these lesions tend to undergo a series of changes with time, and they disappear within $<6$ months. ${ }^{52}$ Moreover, most enhancing lesions tend to show a nodular enhancement pattern. The remaining lesions show a complete or incomplete ringlike enhancement pattern. There are no 


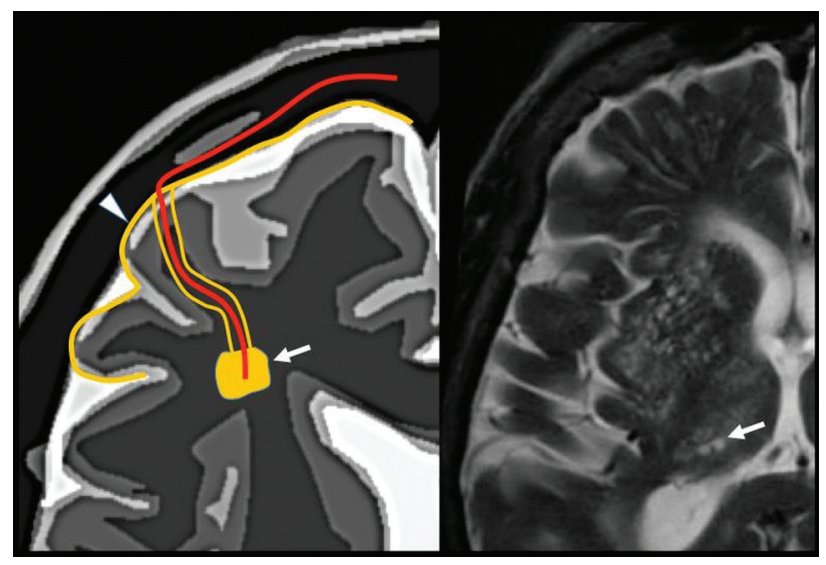

FIG 4. Pathophysiology of the vascular pattern. The picture features the mural and/or endoluminal microvascular lesion that induces the ischemic lesion of the parenchyma. Arrowhead indicates periarteriole and arrow indicates periarteriole inflammation. Image modified with permission from Martorell et al. ${ }^{56}$

histologic differences between these 2 distinct types of enhancement patterns, ${ }^{50,53,54}$ and the differences may be due to the lesion size and/or the timing of scanning after $\mathrm{Gd}^{3+}$ administration, which reflects the capability of $\mathrm{Gd}^{3+}$ to fill the lesion but not the surrounding normal tissue. ${ }^{48,53,54}$

Several studies ${ }^{48,52}$ have established a correlation between enhancement pattern and the magnetization transfer ratio (MTR). During MTR, magnetization is transferred from the mobile proton pool to the immobile one. The resulting signal density in the mobile pool gives a signal reduction. It allows subcategorization of MS lesions into those with very low MTR such as demyelinating lesions and slightly low MTR as in edematous lesions. Its major advantage is that it is a sensitive parameter to quantify the integrity of myelinated WM (both demyelinated and remyelinated tissue) in the absence of axonal loss. ${ }^{55}$ Additionally, it has been suggested that the nodular enhancing lesions have the highest MTR, while ringlike enhancing lesions have the lowest MTR. Nevertheless, lesion enhancement can depend on many other factors, including the dosage of contrast agent, the time from injection to imaging, the magnitude of $\mathrm{BBB}$ abnormalities, magnetic field strength, concurrent steroid use, and the MR imaging pulse sequence parameters used between each study.

Basic Pathophysiology. One possible mechanism of damage to the WM is through the involvement of a cerebral venule or an arteriole, which provides the blood supply of the parenchyma that depends on the vasculature. ${ }^{56}$ White matter microvascular disease involves a broad range of conditions such as infection, hypoxia-ischemia, atherosclerosis, granulomatous or nongranulomatous inflammation, among others. Radiologically, it can manifest as focal lesions in the WM or in paravascular spaces. It may have a noninfectious inflammatory etiology (as is the case of MS), an atypical infectious etiology, a metabolic etiology, or a traumatic etiology (diffuse axonal injury).

Types. The differential diagnosis of multiple hyperintense punctate images in the white matter on T2-weighted sequences is manifold, and many of these entities must be excluded to make the diagnosis of MS. On the basis of several semiological elements, 3

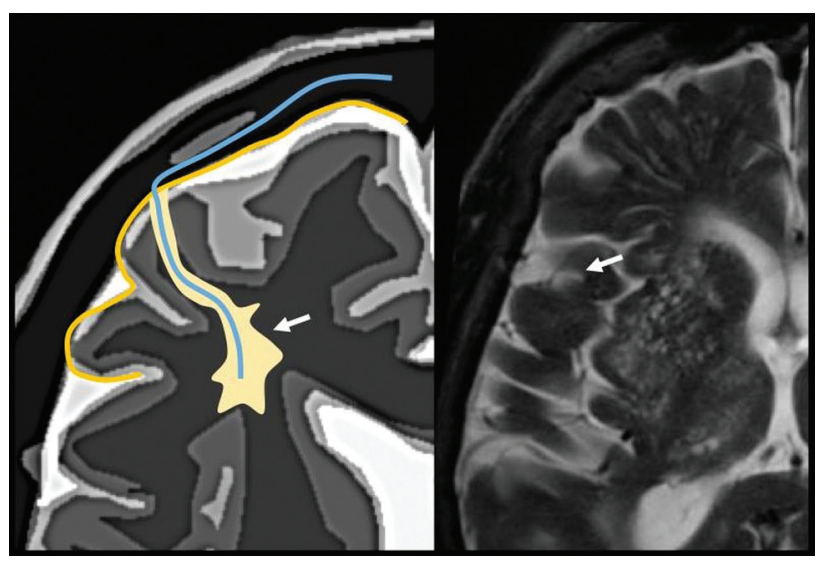

FIG 5. Pathophysiology of the perivascular pattern, the arrows represent perivenular inflammation from the perivenular space. The picture features a perivascular pathologic process and the adjacent parenchymal lesion. The demyelinating layer is caused by perivenular inflammation in a patient with multiple sclerosis. Image modified with permission from Martorell et al. ${ }^{56}$

main patterns can be identified. The first is a vascular pattern, which is caused by an arteriolar lesion and is the most prevalent, seen in the elderly with atherosclerotic risk factors (leukoaraiosis) (Fig 4). The second is a perivascular pattern, which is caused by perivascular inflammation. ${ }^{57}$ The paradigm of this pattern is MS, for which autoimmune perivenular inflammation has been implicated as the etiology of the demyelination (Fig 5). The third is a nonspecific pattern, ${ }^{58}$ which is also usually caused by microvascular disease.

Distribution and Location. Hyperintense punctate foci in the WM may present with a predominantly supratentorial, infratentorial, or mixed distribution. ${ }^{56}$ The presence of lesions with a supratentorial distribution suggests small-vessel disease as a first option, which favors a vascular pattern. The concurrent finding of striatocapsular or deep GM lacunes also supports this diagnosis, as does hemosiderin deposition in hypertension-related GM lesions. A lesion is regarded as periventricular when it is in contact or virtually in contact with the ependymal surface of the ventricle. ${ }^{59}$ Infratentorial lesions can have either a peripheral or central location closer to the brain stem or fourth ventricle. A peripheral lesion is typically associated with a perivascular pattern, whereas a central lesion is generally associated with a vascular pattern. ${ }^{56}$

In the past decade, the focus in MS research has switched from WM to GM involvement. ${ }^{60}$ Unfortunately, cortical lesions (juxtacortical, intracortical, and subpial GM lesions) remain difficult to detect without high-resolution MR imaging, using a standard field strength. The most likely reason for the difficulty is their relatively small size. ${ }^{61}$ Moreover, the difference in pathologic substrate, anatomic paucity of myelin in the cortex generating little MR imaging contrast on demyelination, and partial volume effects from adjacent CSF and WM probably play a role. Many in vivo studies have shown improved detection using higher magnetic field strengths up to $7 \mathrm{~T} .{ }^{62}$ The implementation of 7T MR imaging has resulted in an increased detection of cortical (enhancing) lesions in patients with MS, compared with the lower 3T and 1.5T MR imaging systems. ${ }^{63}$ Although the first results with 7T seem promising, several questions still remain to be answered. 


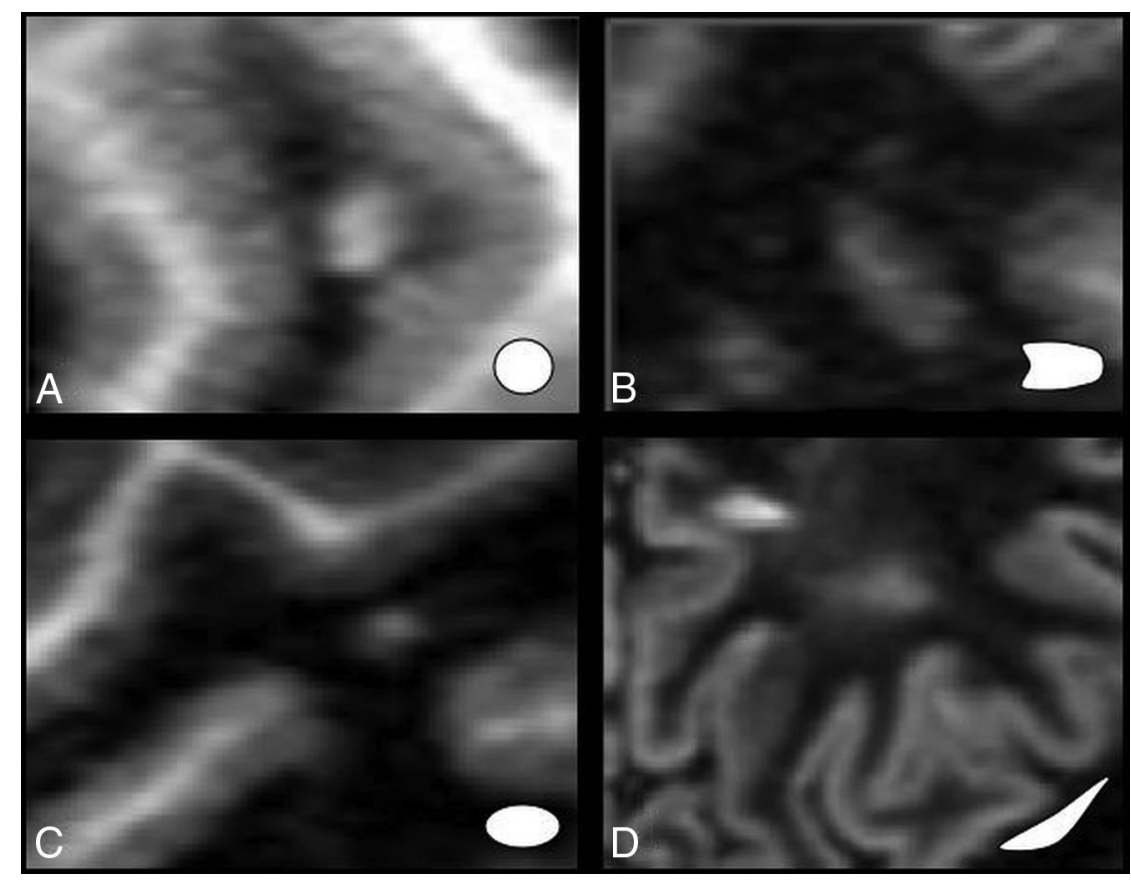

FIG 6. Types of lesion patterns: specific $(A$ and $B)$ versus nonspecific $(C$ and $D)$.
Morphology, Size, and Changes with Time. Lesions can be of several shapes: oval or fusiform and punctate, linear, nodular, or round (Fig 6). Punctate, roundish, and amorphous lesions are nonspecific. On the other hand, oval or fusiform lesions may have a distribution parallel to the cerebral microcirculation, and they have a perivascular pattern. Oval or fusiform periventricular lesions in a radial pattern are a common feature of MS. They are known as Dawson fingers. The confluence of these lesions makes up a ridgelike configuration, which is also associated with MS. ${ }^{56}$

Localization of an isolated lesion of $>10-15 \mathrm{~mm}$ is suggestive of a perivascular pattern. Smaller lesions are nonspecific and can be indicative of either a microvascular or a perivascular lesion. ${ }^{56}$ With time, lesion shape changes from round punctate to oval or fusiform.

Leptomeningeal Enhancement. Menin-

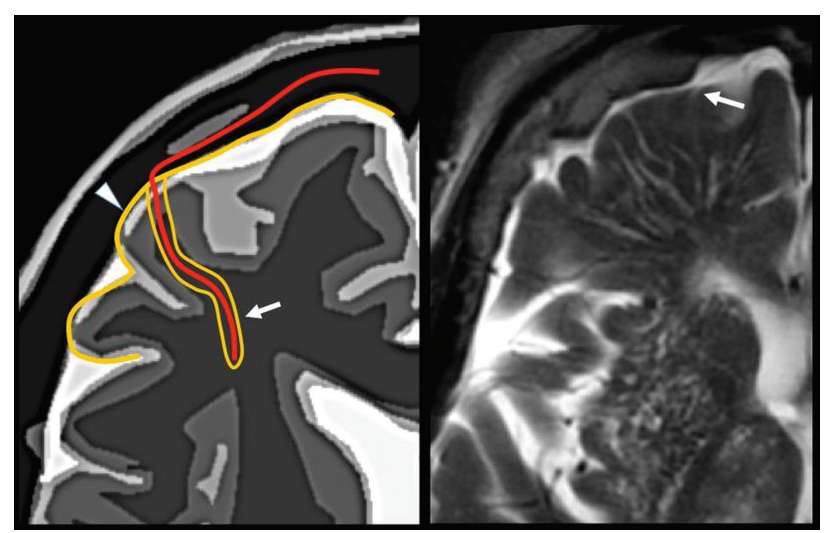

FIG 7. Periarteriolar space of the pial arterioles is surrounded by 1 leptomeningeal layer that separates it from the subpial space (arrow). The periarteriolar space of lenticulostriated arterioles is surrounded by 2 leptomeningeal layers that separate it from the subpial space (arrowhead). Image modified with permission from Martorell et al. ${ }^{56}$

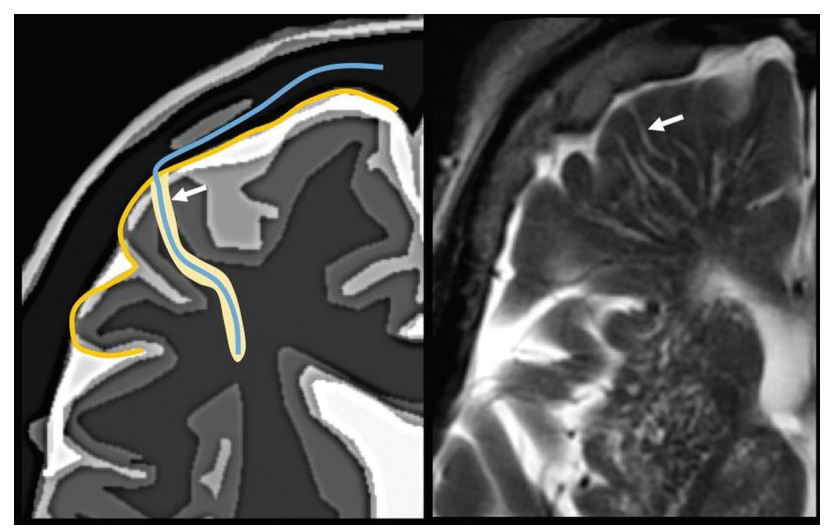

FIG 8. Perivenular space. Communication with the subpial space (arrow). Image modified with permission from Martorell et al. ${ }^{56}$ geal inflammation is rapidly becoming an area of focus in histopathologic findings in multiple sclerosis. ${ }^{64}$ Meningeal inflammation is a consequence of the long-term disease processes of MS. Recent studies $^{65,66}$ have found that $3 \mathrm{~T}$ imaging demonstrated minimal amounts of leptomeningeal enhancement compared with 7T. ${ }^{64}$ Additionally, there was an association with reduced cortical gray matter volumes, which may represent blood-meningeal barrier breakdown near sites of meningeal inflammation.

\section{Artifact-Mimicking Lesions}

Perivascular Spaces. The perivascular space surrounds the wall of arteries and arterioles and veins and venules communicating with the subarachnoid space along the intraparenchymatous course of the vessels. The superficial or cortical arterioles are surrounded by 1 layer of leptomeninges that separates the vascular surface from the periarteriolar space (Fig 7). The pia mater limits the parenchymal surface of this area. The perivascular space of the penetrating arterioles of the basal ganglia is constrained by the 2 layers of leptomeninges that border their endothelium. There is a direct communication of the superficial and deep perivenular space with the subpial space, with no leptomeningeal layers separating them (Fig 8). ${ }^{67,68}$ Fortunately, the advent of FLAIR scanning has nearly eliminated any confusion between perivascular spaces which, like CSF, are dark on FLAIR scans, versus MS plaques, which are bright on FLAIR. Only "black holes" of complete myelin loss are dark on FLAIR.

\section{CONCLUSIONS}

Understanding the pathophysiology of lymphocyte-driven inflammation in MS, lesion enhancement patterns, the effect of $\mathrm{Gd}^{3+}$ on the $\mathrm{BBB}$, and the glymphatic system as well as lesion mimics is pivotal in this debilitating autoimmune disease. By understanding the imaging variations that determine the radiologic 
differential diagnosis, one can make a more accurate and timely diagnosis of MS. These concepts explain the variable appearance of the MS lesions in space and time.

Disclosures: David M. Yousem—UNRELATED: Expert Testimony: medicolegal-consulting expert witness; Payment for Lectures Including Service on Speakers Bureaus: American College of Radiology Education Center courses*; Royalties: Elsevier for 5 published books. *Money paid to the institution.

\section{REFERENCES}

1. Rocca MA, Absinta M, Filippi M. The role of advanced magnetic resonance imaging techniques in primary progressive MS. J Neurol 2012;259:611-21 CrossRef Medline

2. Río J, Castilló J, Rovira A, et al. Measures in the first year of therapy predict the response to interferon beta in MS. Mult Scler 2009;15: 848-53 CrossRef Medline

3. Bou Fakhredin R, Saade C, Kerek R, et al. Imaging in multiple sclerosis: a new spin on lesions. J Med Imaging Radiat Oncol 2016; 60:577-86 CrossRef Medline

4. Wu GF, Alvarez E. The immunopathophysiology of multiple sclerosis. Neurol Clin 2011;29:257-78 CrossRef Medline

5. Love S, Louis DN, Ellison DW. Greenfield's Neuropathology. 8th ed. London: Hodder Arnold; 2008

6. Keegan M, König F, McClelland R, et al. Relation between humoral pathological changes in multiple sclerosis and response to therapeutic plasma exchange. Lancet 2005;366:579-82 CrossRef Medline

7. Henderson AP, Barnett MH, Parratt JD, et al. Multiple sclerosis: distribution of inflammatory cells in newly forming lesions. Ann Neurol 2009;66:739-53 CrossRef Medline

8. de Rosbo NK, Kaye JF, Eisenstein M, et al. The myelin-associated oligodendrocytic basic protein region MOBP15-36 encompasses the immunodominant major encephalitogenic epitope(s) for SJL/J mice and predicted epitope(s) for multiple sclerosis-associated HLA-DRB1*1501. J Immunol 2004;173:1426-35 CrossRef Medline

9. Greer JM, Csurhes PA, Cameron KD, et al. Increased immunoreactivity to two overlapping peptides of myelin proteolipid protein in multiple sclerosis. Brain 1997;120(Pt 8):1447-60 CrossRef Medline

10. Pette M, Fujita K, Wilkinson D, et al. Myelin autoreactivity in multiple sclerosis: recognition of myelin basic protein in the context of HLA-DR2 products by T lymphocytes of multiple-sclerosis patients and healthy donors. Proc Natl Acad Sci U S A 1990;87:7968-72 CrossRef Medline

11. Valli A, Sette A, Kappos L, et al. Binding of myelin basic protein peptides to human histocompatibility leukocyte antigen class II molecules and their recognition by $\mathrm{T}$ cells from multiple sclerosis patients. J Clin Invest 1993;91:616-28 CrossRef Medline

12. Zhang J, Markovic-Plese S, Lacet B, et al. Increased frequency of interleukin 2-responsive $\mathrm{T}$ cells specific for myelin basic protein and proteolipid protein in peripheral blood and cerebrospinal fluid of patients with multiple sclerosis. J Exp Med 1994;179:973-84 CrossRef Medline

13. Brucklacher-Waldert V, Stuerner K, Kolster M, et al. Phenotypical and functional characterization of $\mathrm{T}$ helper 17 cells in multiple sclerosis. Brain 2009;132(Pt 12):3329-41 CrossRef Medline

14. Durelli L, Conti L, Clerico M, et al. T-helper 17 cells expand in multiple sclerosis and are inhibited by interferon-beta. Ann Neurol 2009;65:499-509 CrossRef Medline

15. Tzartos JS, Friese MA, Craner MJ, et al. Interleukin-17 production in central nervous system-infiltrating $\mathrm{T}$ cells and glial cells is associated with active disease in multiple sclerosis. Am J Pathol 2008;172: 146-55 CrossRef Medline

16. Kebir H, Kreymborg K, Ifergan I, et al. Human TH17 lymphocytes promote blood-brain barrier disruption and central nervous system inflammation. Nat Med 2007;13:1173-75 CrossRef Medline

17. Perry VH, Nicoll JA, Holmes C. Microglia in neurodegenerative disease. Nat Rev Neurol 2010;6:193-201

18. Bodini B, Cercignani M, Toosy A, et al. A novel approach with "skel- etonised MTR" measures tract-specific microstructural changes in early primary-progressive MS. Hum Brain Mapp 2014;35:723-33 CrossRef Medline

19. Broom KA, Anthony DC, Blamire AM, et al. MRI reveals that early changes in cerebral blood volume precede blood-brain barrier breakdown and overt pathology in MS-like lesions in rat brain. J Cereb Blood Flow Metab 2005;25:204-16 CrossRef Medline

20. Lassmann H. Relapsing-remitting and primary progressive MS have the same cause(s): the neuropathologist's view, 1. Mult Scler 2013;19:266-67 CrossRef Medline

21. Karthikeyan K, Mahat MY, Chandrasekaran S, et al. Bioanalytical method development, validation and quantification of dorsomorphin in rat plasma by LC-MS/MS. Biomed Chromatogr 2013;27: 1018-26 Medline

22. Campbell JL, Le Blanc JC. Peptide and protein drug analysis by MS: challenges and opportunities for the discovery environment. Bioanalysis 2011;3:645-57 CrossRef Medline

23. Fernández M, Montalban X, Comabella M. Orchestrating innate immune responses in multiple sclerosis: molecular players. J Neuroimmunol 2010;225:5-12 CrossRef Medline

24. Sloane JA, Batt C, Ma Y, et al. Hyaluronan blocks oligodendrocyte progenitor maturation and remyelination through TLR2. Proc Natl Acad Sci U S A 2010;107:11555-60 CrossRef Medline

25. Mathey EK, Derfuss T, Storch MK, et al. Neurofascin as a novel target for autoantibody-mediated axonal injury. J Exp Med 2007;204: 2363-72 CrossRef Medline

26. Mahad DJ, Ziabreva I, Campbell G, et al. Mitochondrial changes within axons in multiple sclerosis. Brain 2009;132(Pt 5):1161-74 CrossRef Medline

27. Scott $P$. New breakthroughs involving oligodendrocytes and stems cells, and their impact on multiple sclerosis. Microreviews in Cell and Molecular Biology 2012;1. https://undergradsciencejournals.okstate. edu/index.php/MRCMB/article/view/1987. Accessed February 5, 2018

28. Mallik S, Samson RS, Wheeler-Kingshott CA, et al. Imaging outcomes for trials of remyelination in multiple sclerosis. J Neurol Neurosurg Psychiatry 2014;85:1396-404 CrossRef Medline

29. Swanton JK, Fernando K, Dalton CM, et al. Modification of MRI criteria for multiple sclerosis in patients with clinically isolated syndromes. J Neurol Neurosurg Psychiatry 2006;77:830-33 CrossRef Medline

30. Geurts JJ, Calabrese M, Fisher E, et al. Measurement and clinical effect of grey matter pathology in multiple sclerosis. Lancet Neurol 2012;11:1082-92 CrossRef Medline

31. Lorentzen J, Grey MJ, Crone C, et al. Distinguishing active from passive components of ankle plantar flexor stiffness in stroke, spinal cord injury and multiple sclerosis. Clin Neurophysiol 2010;121: 1939-51 CrossRef Medline

32. Obermeier B, Daneman R, Ransohoff RM. Development, maintenance and disruption of the blood-brain barrier. Nat Med 2013;19: 1584-96 CrossRef Medline

33. Goriely A, Geers MG, Holzapfel GA, et al. Mechanics of the brain: perspectives, challenges, and opportunities. Biomech Model Mechanobiol 2015;14:931-65 CrossRef Medline

34. Yasuda T, Fukumura K, Sato Y, et al. Effects of detraining after blood flow-restricted low-intensity training on muscle size and strength in older adults. Aging Clin Exp Res 2014;26:561-64 CrossRef Medline

35. Bammer R, Augustin M, Strasser-Fuchs S, et al. Magnetic resonance diffusion tensor imaging for characterizing diffuse and focal white matter abnormalities in multiple sclerosis. Magn Reson Med 2000; 44:583-91 CrossRef Medline

36. Enzinger C, Barkhof F, Ciccarelli O, et al; MAGNIMS study group. Nonconventional MRI and microstructural cerebral changes in multiple sclerosis. Nat Rev Neurol 2015;11:676-86 CrossRef Medline

37. Lucchinetti CF, Popescu BF, Bunyan RF, et al. Inflammatory cortical demyelination in early multiple sclerosis. N Engl J Med 2011;365: 2188-97 CrossRef Medline 
38. Iliff JJ, Goldman SA, Nedergaard M. Implications of the discovery of brain lymphatic pathways. Lancet Neurol 2015;14:977-79 CrossRef Medline

39. Chaitanya GV, Omura S, Sato F, et al. Inflammation induces neurolymphatic protein expression in multiple sclerosis brain neurovasculature. J Neuroinflammation 2013;10:895 CrossRef Medline

40. Eide PK, Ringstad G. MRI with intrathecal MRI gadolinium contrast medium administration: a possible method to assess glymphatic function in human brain. Acta Radiol Open 2015;4: 2058460115609635 Medline

41. Jessen NA, Munk AS, Lundgaard I, et al. The glymphatic system: a beginner's guide. Neurochem Res 2015;40:2583-99 CrossRef Medline

42. Bakker EN, Bacskai BJ, Arbel-Ornath M, et al. Lymphatic clearance of the brain: perivascular, paravascular and significance for neurodegenerative diseases. Cell Mol Neurobiol 2016;36:181-94 CrossRef Medline

43. Ratner V, Zhu L, Kolesov I, et al. Optimal-mass-transfer-based estimation of glymphatic transport in living brain. Proc SPIE Int Soc Opt Eng 2015;9413 CrossRef Medline

44. Bilston LE, Stoodley MA, Fletcher DF. The influence of the relative timing of arterial and subarachnoid space pulse waves on spinal perivascular cerebrospinal fluid flow as a possible factor in syrinx development. J Neurosurg 2010;112:808-13 CrossRef Medline

45. Kanda T, Nakai Y, Oba H, et al. Gadolinium deposition in the brain. Magn Reson Imaging 2016;34:1346-50 CrossRef Medline

46. Naganawa S, Nakane T, Kawai H, et al. Gd-based contrast enhancement of the perivascular spaces in the basal ganglia. Magn Reson Med Sci 2017;16:61-65 CrossRef Medline

47. Ramalho M, Ramalho J, Burke LM, et al. Gadolinium retention and toxicity: an update. Adv Chronic Kidney Dis 2017;24:138-46 CrossRef Medline

48. Gasperini C, Paolillo A, Rovaris M, et al. A comparison of the sensitivity of MRI after double-and triple-dose Gd-DTPA for detecting enhancing lesions in multiple sclerosis. Magn Reson Imaging 2000;18:761-63

49. McDonald RJ, McDonald JS, Kallmes DF, et al. Gadolinium deposition in human brain tissues after contrast-enhanced MR imaging in adult patients without intracranial abnormalities. Radiology 2017; 285:546-54 CrossRef Medline

50. Smirniotopoulos JG, Murphy FM, Rushing EJ, et al. Patterns of contrast enhancement in the brain and meninges. Radiographics 2007; 27:525-51 CrossRef Medline

51. Gaitán MI, Shea CD, Evangelou IE, et al. Evolution of the bloodbrain barrier in newly forming multiple sclerosis lesions. Ann $\mathrm{Neu}$ rol 2011;70:22-29 CrossRef Medline

52. Tintore $M$, Rovira A. MRI criteria distinguishing seropositive NMO spectrum disorder from MS. Neurology 2013;80:1336 CrossRef Medline

53. Davis PC, Bravo O, Gehrke M, et al. Development and validation of an LC-MS/MS method for the determination of quetiapine and four related metabolites in human plasma. J Pharm Biomed Anal 2010;51: 1113-19 CrossRef Medline

54. Yin H, Davis T, Porter NA. Simultaneous analysis of multiple lipid oxidation products in vivo by liquid chromatographic-mass spectrometry (LC-MS). Methods Mol Biol 2010;610:375-86 CrossRef Medline

55. Fischer M, Kunkel A, Bublak P, et al. How reliable is the classification of cognitive impairment across different criteria in early and late stages of multiple sclerosis? J Neurol Sci 2014;343:91-99 CrossRef Medline

56. Medrano Martorell S, Cuadrado Blázquez M, García Figueredo D, et al. Hyperintense punctiform images in the white matter: a diagnostic approach [in Spanish]. Radiología 2012;54:321-35 CrossRef Medline

57. Ge Y, Law M, Johnson G, et al. Dynamic susceptibility contrast perfusion MR imaging of multiple sclerosis lesions: characterizing hemodynamic impairment and inflammatory activity. AJNR Am J Neuroradiol 2005;26:1539-47 Medline

58. González-Quintanilla V, Oterino A, Toriello M, et al. Cluster-tic syndrome as the initial manifestation of multiple sclerosis. J Headache Pain 2012;13:425-29 CrossRef Medline

59. Takao $\mathrm{H}$, Abe $\mathrm{O}$, Yamasue $\mathrm{H}$, et al. Gray and white matter asymmetries in healthy individuals aged 21-29 years: a voxel-based morphometry and diffusion tensor imaging study. Hum Brain Mapp 2011;32:1762-73 CrossRef Medline

60. Kilsdonk ID, Barkhof F, Wattjes MP. 2010 revisions to McDonald criteria for diagnosis of multiple sclerosis: impact of 3-Tesla magnetic resonance imaging. Ann Neurol 2011;70:182-83 CrossRef Medline

61. Seewann A, Vrenken $\mathrm{H}$, Kooi EJ, et al. Imaging the tip of the iceberg: visualization of cortical lesions in multiple sclerosis. Mult Scler 2011;17:1202-10 CrossRef Medline

62. Grabner G, Dal-Bianco A, Schernthaner M, et al. Analysis of multiple sclerosis lesions using a fusion of 3.0 T FLAIR and 7.0 T SWI phase: FLAIR SWI. J Magn Reson Imaging 2011;33:543-49 CrossRef Medline

63. de Graaf WL, Kilsdonk ID, Lopez-Soriano A, et al. Clinical application of multi-contrast 7-T MR imaging in multiple sclerosis: increased lesion detection compared to $3 \mathrm{~T}$ confined to grey matter. Eur Radiol 2013;23:528-40 CrossRef Medline

64. Harrison AM, das Nair R, Moss-Morris R. Operationalising cognitive fatigability in multiple sclerosis: a Gordian knot that can be cut? Mult Scler 2017;23:1682-96 CrossRef Medline

65. Patejdl R, Penner IK, Noack TK, et al. Multiple sclerosis and fatigue: a review on the contribution of inflammation and immune-mediated neurodegeneration. Autoimmun Rev 2016;15:210-20 CrossRef Medline

66. Absinta M, Cortese IC, Vuolo L, et al. Leptomeningeal gadolinium enhancement across the spectrum of chronic neuroinflammatory diseases. Neurology 2017;88:1439-44 CrossRef Medline

67. Kwee RM, Kwee TC. Virchow-Robin spaces at MR imaging. Radiographics 2007;27:1071-86 CrossRef Medline

68. Pollock H, Hutchings M, Weller RO, et al. Perivascular spaces in the basal ganglia of the human brain: their relationship to lacunes. $J$ Anat 1997;191(Pt 3):337-46 CrossRef Medline 